INTERNATIONAL HIGHER EDUCATION NO. 69 FALL 2012

\title{
Chinese National University Rankings
}

\section{LIU JIN and HONG SHEN}

Liu Jin is a PhD candidate in the School of Education, at Huazhong University of Science and Technology, Wuhan, China. He is a visiting scholar at CIHE at Boston College. E-mail: liujinzju@gmail.com. Hong Shen is professor and vice dean of the School of Education, at Huazhong University of Science and Technology. E-mail: hongshen@mail.hust.edu.cn.

The Academic Ranking of World Universities, published initially by Shanghai Jiao Tong University in China, is well known in the field of international higher education. However, its influence in China-as well as that of Times Higher Education ranking, Webometrics ranking, and other world university rankings-cannot be compared to Chinese national university rankings' influence.

Each year, more than 9 million Chinese high school students attempt to enter universities, by taking the nationwide entrance exam (Gaokao). During this process, the Chinese national university rankings play the most essential role. Unlike America, in China, students find it almost impossible to transfer among universities once they have made a decision. Choosing a university means deciding one's life and future, which makes university selection one of the most significant events to millions of Chinese families. In this process, most families on the Chinese national rankings and world university rankings have a much smaller influence in China, because only few Chinese universities are on the world university ranking lists. 


\section{FOUR MAJOR RANKINGS}

In 1987, the Chinese Academy of Management Science released the first national university ranking. Before that, Chinese society did not care about the university rankings, because Chinese universities lacked competition. Since then, 17 influential national university rankings in China have occurred-among those, 7 have been suspended or disappeared. Each of the rankings declares itself to be nonprofit and that its core mission is to promote the development of higher education in China. However, some of them make a profit by selling ranking books or assisting universities with development plans. Currently, there are four influential national university rankings in China.

Netbig University Ranking. This ranking was developed in 1999 by the Chinese Netbig company, with the stated purpose of helping students' university selection process, which is consistent with the basic idea of the US News $\mathcal{E}$ World Report ranking, except for ranking index and weights. This index system includes 6 first-level indices (university prestige, academic resources, academic achievements, graduates' status and influences, faculty resources, and infrastructure) and 19 second-level indices, which are each given about a 2 percent to 15 percent weight.

Guangdong Institute of Science Management Ranking. This ranking was founded by $\mathrm{Wu}$ Shulian and includes comprehensive subrankings in dozens of categories, such as faculty efficiency and research efficiency. The mission of these comprehensive subrankings is to evaluate contributions of universities to society, by measuring their implementation of main functions. There are 2 first-level indices (students training and scientific research), 4 second-level indices (undergraduate training, graduate training, 
natural science research, and social science research), and 33 third-level indices (e.g., undergraduate employment rate); each of the three levels is given a different weight.

Chinese Alumni Network Ranking. This ranking was initiated by the Chinese Alumni Network, which aims to measure universities' academic potential and contributions to science. This is the first ranking that separates public universities from private universities. This ranking has 3 first-level indices (students' training, scientific research, and comprehensive prestige), 7 second-level indices (scientific research bases, research projects, scientific research, training base, teaching staff, outstanding alumni, and prestige), and 9 third-level indices (scientific innovation, basic research projects, major scientific research, outstanding talent, quality of faculty and academic levels, national reputation, alumni donations, and social prestige). In addition to the comprehensive rankings, this system includes some special classifications-such as, the Chinese University Ranking of Alumni Donation, the Chinese University Ranking of Alumni Fellowship, and the Chinese University Ranking of Nature \& Science Papers.

Research Center for Chinese Science Evaluation Ranking. This ranking, designed by Qiu Junping and his team at Wuhan University, aims to evaluate the competitiveness of universities. The basic idea of the ranking is to divide the university into three categories: (1) top public universities, (2) general public universities, and (3) private universities. Categories of universities are measured by different indicators, which means that this ranking holds a rather large indicator pool. For example, the ranking index of public top universities contains 4 first-level indicators (educational resources, the standard of teaching, scientific research, and university prestige), 13 second-level indicators (e.g., funding for education), and more than 50 third-level indicators (e.g., total campus area). 
In addition to the above rankings, China also contains less-influential rankings. For instance, Renmin University focuses on the ranking of top universities. Chinese University Performance Report, published by the Chinese National Institute of Educational Sciences, is focused on the ratio between university input and output.

\section{Methodology AND DATABASES}

The method of Chinese national rankings is based on setting up a multidimensional index system, giving weight to each index, collecting data, and analyzing the results through metrics. In spite of careful scrutiny and sophisticated calculations in each ranking, ordinary academic observers still believe that these rankings are a reflection of initiators' and executors' personal feelings, rather than rigorous scientific research.

Academic observers also question these rankings' data source. Among the four rankings above, two of them are published by companies, one is hosted by a university, and the other is released by a nonprofit organization. None of them are government agencies, which makes it difficult to obtain access to data. Mainly, in China, serious data are often owned by the government. For most rankings, a majority of data come from secondary sources, which include the Internet, newspapers, magazines, and books. To make matters worse, the information is often pieced together without a clear sense of dates. For instance, in the Guangdong Institutes of Science Management 2011 ranking, some data are from 2010, while others were collected in 2008 and 2009.

\section{CONCLUSION}

Chinese university rankings' existence is related to certain demands: Students require the need to make university choices, and universities must improve their rankings, in 
order to attract the most-qualified students and research funding. The publishers of rankings have the demand of making money.

Chinese national rankings have far-reaching influence and have promoted development of Chinese higher education. However, as more universities attempt to change for adjusting to ranking criteria, problems occur. For example, overestimating the index of research achievement has triggered a publishing boom of large-scale papers in recent years; universities that insist on not expanding the scale of enrollment find it difficult to keep a good place in Chinese university rankings; moreover, questions about the index system itself are increasing. 